\title{
Self- Efficacy of Academic Clinical Nurse Educators for Assuming the Roles of Preceptors
}

\author{
Shereen R. Dorgham ${ }^{1}$,Heba K. Obied ${ }^{2}$ \\ ${ }^{1 .}$ Assistant professor of Nursing Administration, Faculty of Nursing, Tanta University, Egypt. \\ 2. Assistant professor of Nursing Administration, Faculty of Nursing, Tanta University, Egypt.
}

\begin{abstract}
Background: Academic clinical nurse educators' self-efficiency is described as their judgment of their organizational capacity as well as ability to execute actions needed to achieve the stated output level. Aim: This research aimed to assess self- efficacy of academic clinical nurse educators to assume the roles of preceptors for nurse students. Methods: The study conducted in the faculty of nursing, using a descriptive cross-sectional design. Subjects: Consisted of (62) academic clinical nurse educators from different departments. One tool was used to collect the present study data. It contains five tasks; Role model, Educator, Socializer, Evaluator and Preceptor role. Results: More than two thirds of academic clinical nurse educators had high self-efficacy related to the roles through all tasks of the preceptors. Around one third of them had low self- efficacy related to the role of preceptors as educator, evaluator, and preceptor role. Conclusion: the current study illuminated the need to conduct preceptorship program frequently to prepare ACNEs to act as preceptors in clinical education. Additionally, there is disparity of levels of self-efficacy among ACNE to assume the roles of preceptors.
\end{abstract}

\section{Keywords: Academic clinical nurse educators, Roles of preceptors \& Self-efficacy}

\section{Introduction}

Clinical training is the core of nursing education, it is expected in the twenty-first century that nursing students apply a critical view to their work as well as be capable of taking measures for the transformation of reality (Girotto , et al., 2019). Consequently nurse preceptor plays an important role in guiding and role modeling their students; whether being beginning, intermediate, or advanced; to be autonomous practitioners; through positive engagement that inturn improve both students' confidence, social responsibility, practice and think critically (Madhavanpraphakaran, 2013).

Preceptorship programs have positive impact in bridging the gap between theory and practice that experienced by novice nurses and nursing students in clinical settings (Lazarus, 2016; Hardacre \& Hayes, 2016; Elizabeth et al., 2017). Efficient nurse preceptor is required to enroll into a structure or formalized preceptorship training program; which lasts for six months or longer, to ensure that the preceptor demonstrate commitment toward their role as preceptor (Matua et al., 2014; Lewis \& McGowan, 2015).

Effective preceptorship program in undergraduate nursing education is consisted of three main components preceptor, nurse student and faculty member; each has certain role that implied specific responsibilities to achieve the required and designed clinical experience (Girotto, et al., 2019). A nurse preceptor is competent and experienced nurse clinician who is passionate about the nursing profession, aspires to teach, and received formal training. The preceptor's responsibilities entail developing students' clinical skills through assuming role modeling; and communicate professionally with others while demonstrating nursing actions.

A major role for the preceptor is to show appropriate nursing behaviors and act as a role model for both the preceptee students, and the staff nurses who observe this practice (Elizabeth et al., 2017). Other elements that add to the preceptor role is the supervision, assessment and counseling as it strengthens the relationship (Elizabeth et al., 2017; Franklin, 2013). Communication between the preceptor and the preceptee, and the preceptor and the faculty is vital, as it helps the student understand how the expert solves problems and provide patient care. A preceptor should provide a preceptee a timely feedback about positive as well as negative act in such respectful way (Elizabeth et al., 2017). As well as being role model by demonstrating competent independent professional nursing practice (McQueen et al., 2018; Lalonde \&Hall, 2016). Since preceptors are at the center of clinical educational process, it is crucial to assess their self-efficacy of their roles when training future health care professionals.

Self-efficiency has been described by Bandura (1986) as 'People's judgments of their organizational capacity and their ability to execute actions needed to achieve the stated output level. 
It is not enough for individuals to possess the necessary knowledge and skills to be successful functioning; they must also be convinced they can perform the required behavior (s) successfully under typical, importantly, and challenging circumstances. Accordingly, skills and efficacy believed to be fundamental for effective human functioning; these two elements evolve together as individuals grow and learn (Artino, 2012).

Bandura's theory of self-efficacy is a construct centered on the teacher's belief or view of skills to produce a desired outcome (Bandura, 1977). The components of Bandura's theory of self-efficacy describe beliefs of academic clinical nurse educators about their capacity as a preceptor within clinical education. Academic clinical nurse educators conducted an assessment of their competence to act as preceptors for the provision of clinical education skills and knowledge. The self-efficacy of the clinical nurse educators showed their beliefs about their ability to influence students learning through their role as preceptors (Britton, 2017).

Ascertain that new graduate nurses possess the required knowledge, skills, plus professional values pivotal to function independently where teaching hospitals suffer from sever nursing shortage. Accordingly nursing faculties are responsible to equip students with required skills to assume their work responsibilities competently without delay through academic clinical nurse educators in different specialties. Although, the highest ratio between ACNEs and students which contradicted with the nature of preceptorship one to one relationship. There is an intense need to rely on effective preceptors to support nursing students in different clinical setting

(Booth et al., 2016; Dorgahm \& Obied, 2016).

\section{Significant of the study}

Previous studies reported that preceptors are staff nurses who have experiences in clinical practices (Omer, et al., 2016; Elizabeth et al., 2017; Vernon, 2017). However, in the most Arab countries in nursing colleges the academic clinical educators are responsible for the training of undergraduates in different specialties. No previous studies had exposed to this aspect of preceptorship experience. Furthermore, previous researches have been investigated self-efficacy in clinical performance of staff nurses, even in academic they investigated selfefficacy on students' achievements and self-efficacy of educators related to teaching skills and selfefficacy in simulation, rather than clinical nurse educators' self-efficacy for assuming the role as preceptors with students in clinical education (Phuma-Ngaiyaye, et al., 2017; Kimhi et. al., 2016; Garner, et. al., 2018; Britton, 2017).
Hence the present study was the first attempt to emphasize on self-efficacy among academic clinical nurse educator to assume the roles of preceptors for nurse students in clinical education from their perspectives, where they performed without recognition. As well as highlight the needs to hire and prepared more ACNE to perform as preceptors for nurse students in clinical settings rather than unqualified staff nurses.

While the enormous benefits of preceptoship, many challenges restrict its effective utilization including inadequate training for preceptors, inappropriate staff to student ratio, lack of support to preceptors from administration, faculty, educators and cocoordinators. Moreover high workload, lack of time in busy acute care environment, the familiarity of academic staff with the clinical environment can compromised by the requirements of maintaining credibility (especially in relation to keeping up to date with trends in clinical practice) in an academic environment (McClure \& Black 2013; Haggerty et al., 2012 ; Ford et al., 2013). Although clinical nurse educators are responsible for clinical training of students, they didn't have any preceptorship programs or certificates to act as the preceptors. So, the aim of this study was to assess the self-efficacy of academic clinical nurse educators from different specialty in collage to assume the roles of preceptors for students in clinical training, highlight the importance to conduct preceptorship program in nursing college to provide high qualified preceptors from academic clinical nurse educators for clinical education and could be added to database related to this issue that didn't study before.

\section{Theoretical Framework}

The current study adopted Bandura self-efficacy based on efficacy beliefs on clinical nurse educators' performance to execute preceptors' roles which including five tasks; foundation of preceptor, educator/coach, socializer, role model and evaluator. In addition, the current study followed reciprocal causation where the performance in one task depends on the performance of the other tasks. Preceptors who have low self-efficacy to accomplish a specific task will avoid it, whereas those who believe their capabilities are more likely to be involved. In fact, it is hypothesized that individuals who feel successful would expend more time and endure longer in the face of challenges than those who are uncertain of their skills.

The tendency for successful people to expend more energy and last for longer is especially important because most personal achievement requires persistent energy. While low self-efficacy is a mechanism of self-limitation. Thus, in order to 
succeed, individuals need a clear sense of taskspecific self-efficacy, connected to resilience in order to face the unavoidable obstacles of life. Perceived self-efficacy is often assessed in educational research using self-report surveys that allow participants to assess the strength of their confidence in their ability to perform the necessary activities (Bandura, 2006 in Artino, 2012). Therefore, nurse educators' participants in this study asked to judge their performance through preceptors' roles.

\section{Theoretical Framework}

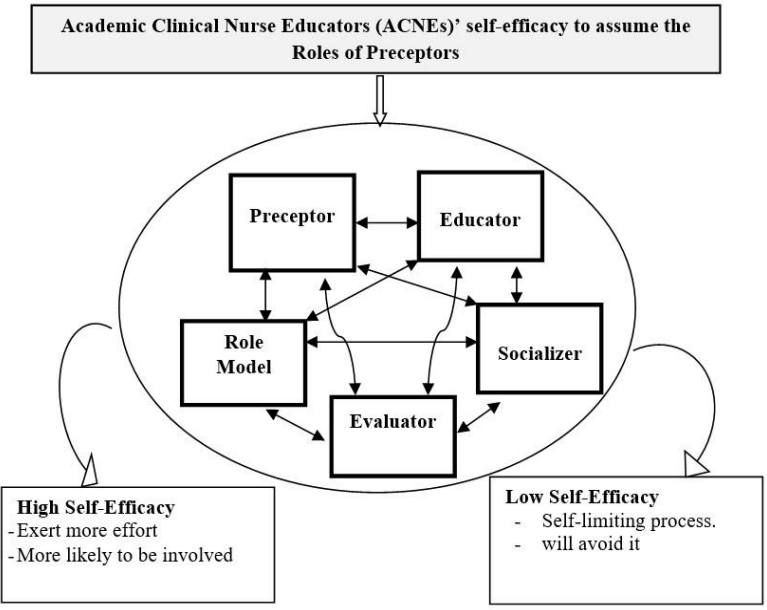

Methodology:

Aim:

This study aimed to assess self- efficacy of academic clinical nurse educators to assume the roles of preceptors for nurse students, and to identifying areas of agreement and disagreement with regard to the roles of preceptors

Also, this study aimed at finding answers to the following questions:

- What is the level of self-efficacy for academic clinical nurse educators to assume the preceptors' roles?

- Which tasks of preceptor's roles have agreement and disagreement regard to the roles of preceptors from their perspectives?

- Is there the relationship between the level of selfefficacy and demographic characteristics among academic clinical nurse educators?

\section{Operational definition:}

Academic clinical nurse educators (ACNEs) are nurse instructors and assistant lecturers who teach undergraduate nursing students in clinical setting. Study design:

Cross-sectional descriptive study design was used to describe the level of self-efficacy regarding to five tasks of preceptors' role. This design was appropriate for collecting data to make inferences about a sample with specific inclusion criteria and describe the relationships among the study variables at one point in time.

Setting:

The study conducted at Tanta University- Faculty of Nursing, included all academic departments (medicalsurgical nursing, nursing administration nursing, pediatric nursing, obstetric nursing, psychiatric nursing, and community nursing).

\section{Subject:}

This research used a convenience sample consisting of (62) academic clinical nurse educators (Male \& Female) from different departments in previous mentioned in settings based on their presence and availability during data collection period. Response rate is $82.7 \%$ of academic clinical nurse educators who decided to engage in the collection of data in the academic year 2018/2019.

Inclusion criteria:

- Nurse instructors and assistant lecturers.

- Teach in clinical areas.

- Had more than one year of experience.

Tool

One tool used to collect the present study data was developed by the researchers after reviewed related literatures (Omer et. al., 2016; Anderson, (2013/2014); Boyer, 2008; Hunsberger, et al., 2000). It included two parts. Part one: ACNEs' characteristics encompass work department, age, academic degree, gender, position, years of experience, number of students in clinical group and receive formal role preparation.

Part two: Self- assessment questionnaire to assess Self- Efficacy of Academic Clinical Nurse Educators if they assume the roles of Preceptors, included 41 statements divided into five subscales: Role model ( 8 statements), Educator (11 statements), Socializer (8 statements), Evaluator (7 statements), Preceptor role (7 statements)

\section{Scoring system}

ACNEs' responses were measured on a three points Likert Scale agree $=3$, uncertain $=2$ and disagree $=1$. The CNEs' total responses were classified into three levels. The subtotal score for each component/ task (role model ranged between 8 or 24 , educator ranged between 11 or 33 , socializer ranged between 8 or 24 , preceptor ranged between 7 or 21 and evaluator ranged between 7 or 21) was calculated separately according to the statements' number, then calculated the total scale score which ranged from 41-123. The ACNEs self- efficacy about the role of preceptors classified in to levels as follows:

- High self- efficacy ranged between 123-92.25 of the total score $(\geq 75 \%)$

- Low self- efficacy less than 92.25 of the total score $(<75 \%)$ 


\section{Method for data collection: \\ Data Collection}

Data were collected through a self-administered questionnaire; it took approximately 10 to 15 minutes for each participant. The data was collected within one month February 2019 during the academic year 2018/2019.

The tool was introduced to a jury of 5 experts to test its face and content validity; based on their opinions certain modifications and changes in statements structure were made. The Content Validity Index was $91 \%$. A pilot study was conducted on $(10 \%)$ of ACNEs to assess the tools' applicability and reliability and they were excluded from the study sample. As well as, the tool was examined for reliability by two times (test-retest reliability) with separate two weeks to be sure from the applicability of the questionnaire and stability of the respondents' answers. The value of Cronbach's coefficient alpha test was equal to 0.78 , and the test-retest reliability value for nominal data was more significant than 0.8 . Ethical considerations:

After the approval of dean of nursing faculty, the purpose of the study was explained to ACNEs and their oral consents to participate were obtained. They were assured about the confidentiality of their data, and the right to withdraw was confirmed. The participation in the study was voluntary without penalty from unwilling participants.

\section{Statistical analysis}

The study data was collected, tabulated and subjected to statistical analysis by SPSS (version 20), also Microsoft office Excel was used for data handling and graphical presentation. Quantitative variables are described by the Mean, and Standard Deviation (SD). Qualitative categorical variables are described by proportions and Percentages.

\section{Results}

Table (1): Distribution of ACNEs' personal characteristic ( $N=62$ )

\begin{tabular}{|c|c|c|c|c|c|}
\hline Items & No. & $\%$ & Items & No. & $\%$ \\
\hline \multicolumn{3}{|l|}{ Position } & \multicolumn{3}{|l|}{ Department (nursing) } \\
\hline Demonstrator & 45 & 72.5 & Obstetric & 11 & 17.7 \\
\hline Assistant lecturer & 17 & 27.5 & Administration & 11 & 17.7 \\
\hline \multicolumn{3}{|l|}{ Gender } & Pediatric & 10 & 16.1 \\
\hline Male & 2 & 3.3 & Psychiatric & 11 & 17.7 \\
\hline Female & 60 & 96.7 & Medical surgical & 12 & 19.4 \\
\hline \multicolumn{3}{|l|}{ Age } & Community & 7 & 11.3 \\
\hline$\leq \mathbf{3 0}$ & 50 & 80.6 & \multicolumn{3}{|l|}{ Academic degree } \\
\hline$>\mathbf{3 0}$ & 12 & 19.4 & Bsc. In nursing & 45 & 72.5 \\
\hline Range & \multicolumn{2}{|c|}{$24-37$} & Master deg. & 17 & 27.5 \\
\hline Mean \pm SD & \multicolumn{2}{|c|}{$28.16 \pm 3.0$} & \multicolumn{3}{|c|}{ Receive formal role preparation } \\
\hline \multicolumn{3}{|l|}{ Years of Experience } & Yes & 0 & $\overline{0}$ \\
\hline$<5$ & 52 & 83.9 & No & 62 & 100 \\
\hline$\geq 5$ & 10 & 16.1 & \multicolumn{3}{|c|}{ No. of students in clinical groups } \\
\hline Range & $1-12$ & & $<25$ & 37 & 59.67 \\
\hline Mean \pm SD & $5.01 \pm 2.23$ & & $\geq 25$ & 25 & 40.23 \\
\hline & & & Range & $15-70$ & \\
\hline
\end{tabular}

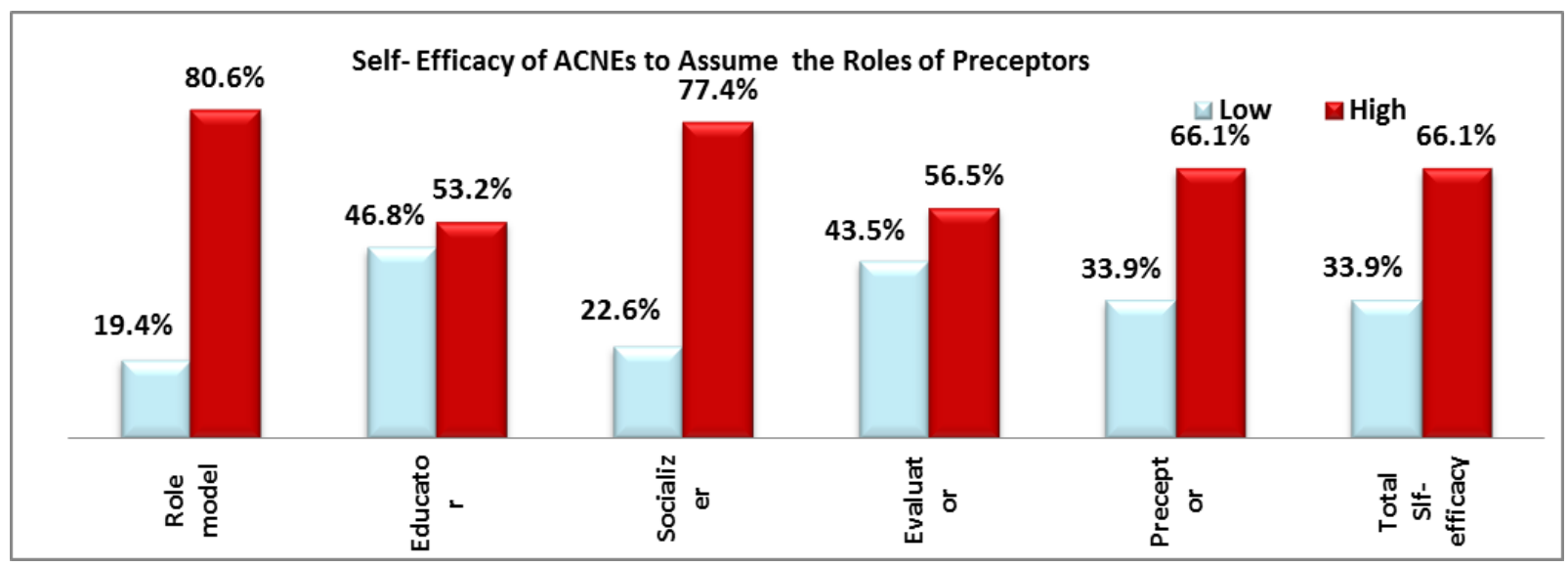

Fig. (2): Self- Efficacy of Clinical Nurse Educators to Assume the Roles of Preceptors 
Table (2): Correlation between ACNEs' age and self-efficacy about the roles of preceptors.

\begin{tabular}{|l|l|l|l|l|l|l|}
\hline $\begin{array}{c}\text { Preceptor } \\
\text { Role } \\
\text { Age }\end{array}$ & Role model & Educator & Socializer & Evaluator & $\begin{array}{l}\text { Preceptor } \\
\text { role }\end{array}$ & Total \\
\hline Coefficient $\mathbf{r}$ & $\mathbf{- 0 . 2 1}$ & $\mathbf{- 0 . 2 8}$ & $\mathbf{- 0 . 2 9}$ & $\mathbf{- 0 . 3 8}$ & $\mathbf{- 0 . 2 6}$ & $\mathbf{- 0 . 3 7}$ \\
\hline P Value & $\mathbf{0 . 0 9 8 0 3}$ & $\mathbf{0 . 0 2 8 7 0} *$ & $\mathbf{0 . 0 2 4 3 0} *$ & $\mathbf{0 . 0 0 2 0 6} * *$ & $\mathbf{0 . 0 4 4 8 7} *$ & $\mathbf{0 . 0 0 3 4 7 * *}$ \\
\hline
\end{tabular}

Table (3): Relation between ACNEs' academic degree and self-efficacy on preceptors' role.

\begin{tabular}{|c|c|c|c|c|c|c|}
\hline Preceptor role & Academic degree & Mean & SD & $\mathbf{t}$ & df & P Value \\
\hline \multirow{2}{*}{ Role model } & Bsc. In nursing & 82.69 & 15.23 & \multirow{2}{*}{0.25} & \multirow{2}{*}{60} & \multirow{2}{*}{0.8020} \\
\hline & Master deg. & 81.73 & 14.59 & & & \\
\hline \multirow{2}{*}{ Educator } & Bsc. In nursing & 76.49 & 16.56 & \multirow{2}{*}{0.62} & \multirow{2}{*}{60} & \multirow{2}{*}{0.5384} \\
\hline & Master deg. & 73.75 & 18.24 & & & \\
\hline \multirow{2}{*}{ Socializer } & Bsc. In nursing & 84.31 & 12.53 & \multirow{2}{*}{1.72} & \multirow{2}{*}{60} & \multirow{2}{*}{0.0902} \\
\hline & Master deg. & 77.57 & 18.29 & & & \\
\hline \multirow{2}{*}{ Evaluator } & Bsc. In nursing & 79.39 & 16.60 & \multirow{2}{*}{1.32} & \multirow{2}{*}{60} & \multirow{2}{*}{0.1902} \\
\hline & Master deg. & 73.54 & 18.04 & & & \\
\hline \multirow{2}{*}{ Preceptor role } & Bsc. In nursing & 85.51 & 15.93 & \multirow{2}{*}{1.48} & \multirow{2}{*}{60} & \multirow{2}{*}{0.1433} \\
\hline & Master deg. & 78.83 & 19.57 & & & \\
\hline \multirow{2}{*}{ Total } & Bsc. In nursing & 81.25 & 11.98 & \multirow{2}{*}{1.34} & \multirow{2}{*}{60} & \multirow{2}{*}{0.1841} \\
\hline & Master deg. & 76.88 & 13.59 & & & \\
\hline
\end{tabular}

Table (4): Relation between ACNEs' Working Department and their self-efficacy Regarding the Roles of preceptors.

\begin{tabular}{|l|l|l|l|l|l|}
\hline Roles of preceptors & Nursing Departments & Mean & SD & F & P Value \\
\hline \multirow{4}{*}{$\begin{array}{l}\text { Total } \\
\text { preceptors }\end{array}$} & Community & 81.19 & 12.27 & & \multirow{3}{*}{} \\
\cline { 2 - 4 } & Obstetric & 78.05 & 12.26 & \multirow{3}{*}{$\mathbf{0 . 7 6}$} & \multirow{2}{*}{$\mathbf{0 . 5 8 4 3}$} \\
\cline { 2 - 4 } & Administration & 78.82 & 10.33 & \\
\cline { 2 - 4 } & Pediatric & 77.93 & 13.02 & & \\
\cline { 2 - 4 } & Psychiatry & 85.36 & 15.54 & & \\
\cline { 2 - 4 } & Medical surgical & 75.61 & 13.24 & & \\
\hline
\end{tabular}

Table (1): Shows distribution of ACNEs' personal characteristic. Around three quarters $(72.5 \%)$ of the studied ACNEs were demonstrators, nearly all $(96.7 \%)$ of them were females. Majority $(80.6 \%)$ of them had less than or equal 30 years old, with mean age 28.16 \pm 3.0. Majority of the ACNEs had less than 5 years of experience and all of them did not receive formal preparation for their role as preceptors. According to number of students in clinical groups more than two fifths of ACNEs worked with groups more than or equal 25 students.

Fig. (1): Illustrates self- efficacy of ACNEs to assume the roles of preceptors. More than two thirds (66.1\%) of ACNE had high self-efficacy related to the roles through all components/ tasks of the preceptors. While, around one third (33.9\%) of the ACNEs had low self- efficacy regarding the roles of preceptors. Around one third of them had low selfefficacy related to the role of preceptors as educator, evaluator, and preceptor role.

Table (2): Shows correlation between ACNEs' age and self-efficacy about the roles of preceptors. The table illustrates that there was high statistical significant negative correlation between ACNEs' age and their self-efficacy related to the roles of preceptors at $\mathrm{p}=<0.01$.

Table (3): Shows relation between ACNEs' academic degree and self-efficacy on preceptors' roles. The table illustrates that there was no statistical significant relation between ACNEs' academic degree and selfefficacy regarding the roles of preceptors.

Table (4): Relation between ACNEs' working department and their self-efficacy regarding the roles of preceptors. The table illustrates that there was no statistical significant relation between CNEs' working department and their self-efficacy regarding the roles of preceptors

\section{Discussion}

ACNEs' self-efficacy is crucial indicator for their capacity to perform their role as preceptors. Results of the present study revealed that more than two thirds of ACNEs had high self-efficacy level related to their perceptions through all components of the roles of preceptors. This result may be due to their experience in clinical education and their awareness 
of the roles of clinical instructors that covered some components of the roles of preceptors. This result is supported with Britton (2017), who stated that the higher self-efficacy is achieved by understanding and experience which influences teaching behaviors and professional progress.

Results of the current study revealed that over three quarters of the ACNEs perceived that they are attentive listener, track practice standards, and follow professional behavior. These findings are in accordance with the literature which reported that the preceptors' roles are to ensure that students follow the acceptable standards of care including adherence to agency protocols, policies, specialty practice guidelines, standards of practice, licensing guidelines, scope of practice and vendor's directions for use of equipment or special treatments. In addition, they are helping in the development of capability and skills by supporting experiential learning establish the safe learning environment in which the novice practices skills and develops capability (Omer, et. al., 2016). Findings also revealed that over one third of the ACNEs were uncertain to accept others' diversity, being exemplar for accessing to evidences, and model reflective practice. Also more than quarter of them was uncertain to provide constructive feedback, and spoke for themselves. These results are in agreement with McQueen et al (2018) expressed that giving and accepting useful feedback is considered as a huge issue for preceptors, and they need to know how to extend their capacity to encourage learning by empowering reflection on understanding care and organizing a range of insightful activities.

Finding of the present study showed that more than two fifths of ACNEs are uncertain that they protected patient from preceptee error and protected the preceptee from making errors. These results may relate to ECNEs limited experience and lack of their preparation to carry their role in protecting patients, colleagues and themselves by ensuring safe student who follow agency protocols and provides safe, effective care, as well as instability and haziness of the clinical learning environment in which they assumed function as preceptors. These findings are contradicted with the literature which indicated that the protector role to protect those they precept from adverse behaviors of colleagues, or assist them in dealing with patient threatening behaviors and from making mistakes that would jeopardize others.

(Omer, et al., 2016).

Results of the current study showed that there were high statistical significant negative correlation between ACNEs' age and their perceived level of self-efficacy regarding performance as preceptors at $\mathrm{p}=<0.01$. These results may be attributed to the conflict that may arise from varies role expectations and different generations, where younger ACNEs were preseptees during their internship year and sort of live this experience, while older ACNEs did not had preceptors during their internship.

Moreover, there was no statistical significant relation between ACNEs' academic degree as well as working department and their self-efficacy regarding their perceptions to assume roles of preceptors. This can be justified as the different academic departments where ACNEs work almost provide the same work experience and workload, and carry out the same duties with students and nurse interns moreover they did not receive any support or orientation for this additional role. These results are contradicted with Lalonde \& Hall (2017) they found there were positive correlations between self-efficacy and age and that academic qualifications should be considered as an important criterion when choosing preceptors of undergraduate nursing students.

\section{Conclusion:}

The current study illuminated the need to conduct preceptorship program frequently to prepare ACNEs to act as preceptors in clinical education. Additionally, there was disparity of levels of selfefficacy among ACNE to assume the roles of preceptors, where two thirds of them had high selfefficacy regarding the role of preceptors as all. There was high statistical significant negative correlation between self-efficacy and ACNEs' age. Although there was no statistical significant relation between both ACNEs' academic degree and department and self-efficacy to assume the roles of preceptors.

\section{Recommendation}

Based on the findings of the present study, the following are recommended;

- College of nursing should establish preceptorship program to prepare ACNEs to act as preceptors in clinical education

- College of nursing should improve ACNE/students ratio by hiring more ACNEs.

- Further studies to assess the effects of ACNEs' performance as preceptors on students' satisfaction

\section{Limitation of the Study}

There are some limitations in the current study; generalization of findings was partly restricted due to the convenient sample and the research performed in one setting.

\section{References:}

- Girotto, L., Enns, S., de Oliveira, M., Mayer, F., Perotta, B., Santos, I., \& Tempski, P. (2019): Preceptors' perception of their role as 
educators and professionals in a health system. BMC medical education, 19(1), 203.

- Madhavanpraphakaran, G., Shukri, R., \& Balachandran, S. (2013): Preceptors' perceptions of clinical nursing education. The Journal of Continuing Education in Nursing, 45(1), 28-34.

- Lazarus, J. (2016): Precepting 101: teaching strategies and tips for success for preceptors. Journal of midwifery \& women's health, 61(S1), 11-21.

- Hardacre, R., \& Hayes, L. (2016): The transition to becoming a newly qualified nurse: A reflection. Journal of New Writing in Health and Social Care, 2(2), 32-43.

- Elizabeth Kamolo BScN KRCHN, M., \& Rachael Vernon, R. (2017): A Critical Review of Preceptor Development for Nurses Working with Undergraduate Nursing Students. International Journal Of Caring Sciences, 10(2), 1089.

- Matua, G., Seshan, V., Savithri, R., \& Fronda, D. (2014): Challenges and strategies for building and maintaining effective preceptor-preceptee relationships among nurses. Sultan Qaboos University Medical Journal, 14(4), e530.

- Lewis, S., \& McGowan, B. (2015): Newly qualified nurses' experiences of a receptorship. British Journal of Nursing, 24(1), 40-43.

- Franklin, N. (2013): Clinical supervision in undergraduate nursing students: a review of the literature', Journal of Business Education \& Scholarship of Teaching, 7 (1):34-42.

- McQueen, K., Poole, K., Raynak, A., \& McQueen, A. (2018): Preceptorship in a nurse practitioner program: The student perspective. Nurse educator, 43(6), 302-306.

- Lalonde, M., \& McGillis Hall, L. (2017): Preceptor characteristics and the socialization outcomes of new graduate nurses during a preceptorship programme. Nursing open, 4(1), 2431.

- Bandura, A. (1986): Social foundations of thought and action. Englewood Cliffs, NJ, 1986, 23-28.

- Artino, A. (2012): Academic self-efficacy: from educational theory to instructional practice. Perspectives on medical education, 1(2), 76-85.

- Bandura, A. (1977). Self-efficacy: Toward a unifying theory of behavioral change. Psychological Review, 84(2), 191-215. doi:10.1037/0033-295X.84.2.191

- Britton, K. (2017): Descriptive comparative study of nursing faculty self-efficacy in the simulation setting. Doctoral Dissertation, Capella University.
- Booth, T., Emerson, C., Hackney, M., \& Souter, S. (2016): Preparation of clinical nurse educators. Nurse Education in Practice, 19,54-57

- Dorgham, S. \& Obeid, H. (2016): Factors affecting nurse interns' compliance with standard precautions for preventing stick injury. Journal of Nursing Education and Practice, 6(12), 121-130

- Omer, T., Suliman, W., \& Moola, S. (2016): Roles and responsibilities of nurse preceptors: Perception of preceptors and preceptees. Nurse education in practice, 16(1), 54-59.

- Vernon, R. (2017): A critical review of preceptor development for nurses working with undergraduate nursing students. International Journal of Caring Sciences, 10(2), 1089.

- Phuma-Ngaiyaye, E., Bvumbwe, T., \& Chipeta, M. (2017): Using preceptors to improve nursing students' clinical learning outcomes: A Malawian students' perspective. International Journal of Nursing Sciences, 4(2), 164-168.

- Kimhi, E., Reishtein, J., Cohen, M., Friger, M., Hurvitz, N., \& Avraham, R. (2016): Impact of simulation and clinical experience on self-efficacy in nursing students: intervention study. Nurse Educator, 41(1), E1-E4.

- Garner, S., Killingsworth, E., Bradshaw, M., Raj, L., Johnson, S., Abijah, S. \& Victor, S. (2018): The impact of simulation education on self-efficacy towards teaching for nurse educators. International nursing review, 65(4), 586-595.

- McClure, E., \& Black, L. (2013): The role of the clinical preceptor: an integrative literaturereview. Journal of Nursing Education.

- Haggerty, C., Holloway, K., \& Wilson, D. (2012): Entry to nursing practice preceptor education and support: could we do it better? Nursing Praxis in New Zealand, 28(1).

- Ford, K., Courtney-Pratt, H., \& Fitzgerald, M. (2013): The development and evaluation of a preceptorship program using a practice development approach. Australian Journal of Advanced Nursing, The, 30(3), 5.

- Bandura, A. (2006): Guide for constructing selfefficacy scales. Self-efficacy beliefs of adolescents, 5(1), 307-337. 